\title{
Effects of increased arterial pressure on blood flow in the damaged brain
}

\author{
J. D. Miller, J. GARIBI, J. B. NORTH, AND G. M. TEASDAlE \\ From the University Department of Neurosurgery, Institute of Neurological Sciences, \\ Southern General Hospital, Glasgow
}

SYNOPSIS The effect of induced arterial hypertension on cerebral blood flow and intracranial pressure was measured before and after the production of a standard cryogenic brain lesion in 10 anaesthetized, ventilated baboons. Before injury the animals were divided into a group with intact autoregulation, having more than $20 \%$ increase in cerebrovascular resistance during arterial hypertension, and a group with impaired autoregulation, in which the change in cerebrovascular resistance was much less. The cryogenic injury produced a rapid rise in intracranial pressure and a reduction of cerebral blood flow in the affected hemisphere. Despite this, there was an increase in cerebrovascular resistance during arterial hypertension in all animals after brain injury, accompanied by a further significant rise in intracranial pressure. It is suggested that this response is unlikely to represent normal physiological autoregulation and caution should be exercised in interpreting it as such in the course of studies of cerebral blood flow in patients with acute brain damage.

Patchy ischaemic brain damage is present in the majority of patients with fatal head injuries (Graham and Adams, 1971). Raised intracranial pressure is also common in patients with head injuries (Troupp, 1965; Johnston et al., 1970).

Although there is not a direct relationship between high intracranial pressure and the occurrence of ischaemia, a sizeable proportion of the ischaemic lesions is of the boundary zone type associated with reductions in cerebral perfusion pressure (Jennett et al., 1973).

Cerebral perfusion pressure is properly defined as the difference between arterial pressure in vessels entering the intracranial subarachnoid space and pressure in the veins leaving it. During alterations in both arterial and intracranial pressure, subarachnoid venous pressure changes in parallel with intracranial pressure; cerebral perfusion pressure is therefore nearly equivalent to the difference between arterial and intracranial pressure (Shulman, 1965; Yada et al., 1973; Johnston and Rowan, 1974). This pressure difference is also equivalent to intracranial arterial transmural pressure (Farrar and Roach,

(Accepted 26 February 1975.)
1973; Miller et al., 1972). Both cerebral perfusion pressure and intracranial arterial transmural pressure, which are determinants of cerebral blood flow, are decreased by a fall in arterial pressure or by rising intracranial pressure. Conversely, they may be augmented either by increasing arterial pressure or by reducing raised intracranial pressure.

In normal circumstances, cerebral blood flow remains constant during changes in arterial pressure between 60 and $150 \mathrm{mmHg}$ (Rapela and Green, 1964; Harper, 1966). This implies an increase in cerebrovascular resistance with arterial hypertension and a decrease in resistance during arterial hypotension, a process called by common usage 'autoregulation' (Johnson, 1964). When arterial pressure is less than $60 \mathrm{mmHg}$ this mechanism of vasodilatation of resistance vessels is taken beyond its limit and flow falls. When mean arterial pressure rises much above $150 \mathrm{mmHg}$ there is a 'breakthrough' of the autoregulatory vasoconstriction and cerebral blood flow rises (Strandgaard et al., 1974). When autoregulation is impaired, no matter the cause of that impairment, cerebrovascular resistance no longer responds adequately and cerebral blood 
flow changes passively with cerebral perfusion pressure. Increases in intracranial pressure in experimental conditions do not cause reduction in cerebral blood flow until the difference between arterial and intracranial pressure falls to 40 mmHg (Rapela and Green, 1964; Häggendal et al., 1970; Miller et al., 1972, 1973; Johnston et al., 1972, 1973; Symon et al., 1973). This maintenance of flow in the face of rising intracranial pressure probably represents another aspect of the same autoregulatory mechanism, since it occurs only when autoregulation to changes of arterial pressure is known to be intact; when autoregulation is impaired flow falls as soon as intracranial pressure increases (Miller et al., 1972, 1973).

These experimental observations suggest that changes in both arterial and intracranial pressure may be considered to affect cerebral blood flow by their influence on cerebral perfusion pressure and transmural pressure, the extent of the change in flow being determined by the degree of autoregulatory function present. The relevance of this in patients with head injury is that brain trauma, even of a trivial nature, is known to impair autoregulation of cerebral blood flow (Brock, 1968; Reivich et al., 1969). In such patients, therefore, variations in the difference between arterial and intracranial pressure may be expected to cause corresponding passive changes in blood flow in damaged areas of brain. Areas of ischaemic brain damage may therefore be explained by reductions in arterial pressure, by increased intracranial pressure, or by moderate changes in both variables occurring simultaneously. On similar theoretical grounds, the way to prevent or ameliorate such ischaemic damage would be to increase cerebral perfusion pressure by reducing intracranial pressure, or, if this is not possible, by increasing arterial pressure.

The effect of induced arterial hypertension on cerebral blood flow in patients with head injuries has been studied by Bruce and his colleagues (1973) and by Overgaard and Tweed (1974). Many patients showed passive increases in blood flow indicating impairment of autoregulation, but some showed apparent autoregulation with no increase in flow even in areas of the brain shown to be damaged and swollen on angiography. Interpretation of data was compli- cated by variable rises in intracranial pressure and increased arterial pressure was not associated with clinical improvement, whether or not cerebral blood flow increased.

These investigations illustrate some of the problems which result when data from simple experimental models are compared with studies in patients. In the latter, measurements of the responses of intracranial pressure and cerebral blood flow in the presence of severe brain damage present several difficulties because many of the variables are hard to control and ethical considerations limit the extent to which cerebrovascular reactivity may be tested. In the experimental animal, the several physiological variables can be well controlled, but the simpler models of intracranial hypertension are quite dissimilar to most clinical conditions, which are secondary to damage of brain parenchyma with areas of contusion, ischaemia, and oedema.

The purpose of the present study was to examine the effects of induced increases in arterial pressure on cerebral blood flow i baboons before and after the production of experimental brain lesions of a type which would simulate the swollen, contused areas seen in patients with head injury. The acute cryogenie injury described by Clasen and his colleagues in 1953 was selected as the most suitable for this purpose; this has been extensively used by one of the authors (Miller et al., 1970).

\section{METHODS}

Ten adult baboons, body weight $10.1 \pm 1.2 \mathrm{~kg}$ (SD) were premedicated with phencyclidine $(1 \mathrm{mg} / \mathrm{kg})$; anaesthesia was induced with intravenous pentothal $(10 \mathrm{mg} / \mathrm{kg})$ and maintained with nitrous oxide and oxygen $(75: 25)$ after intubation, and supplemented by phencyclidine ( $2 \mathrm{mg}$ ) every 30 minutes. Muscular relaxation was obtained with intramuscular succinylcholine $(100 \mathrm{mg})$ repeated every 30 minutes. The baboons were ventilated using a Palmer pump, the stroke volume of which was adjusted to maintain normocapnia $(40 \mathrm{mmHg})$. Body temperature was held constant $\left(38^{\circ} \mathrm{C}\right)$ by intermittent heating.

Arterial pressure was measured from one femoral artery, and a second arterial line was advanced from the other femoral artery to the upper part of the descending aorta for withdrawal of samples for blood gas analysis and for infusion of noradrenaline solution to increase arterial pressure. Intracranial pressure was measured from a catheter introduced 
through a small parasagittal drill hole in the skull into the lateral ventricle; in five of the 10 baboons bilateral ventricular fluid pressure measurements were made.

End-tidal $\mathrm{CO}_{2}$ and body temperature were monitored continuously; arterial $\mathrm{PCO}_{2}, \mathrm{pH}$, and $\mathrm{PO}_{2}$ were measured intermittently using a direct reading electrode system (Radiometer BMS 3) and the results corrected for any temperature difference between the baboon and the recording system in excess of $0.5^{\circ} \mathrm{C}$ (Severinghaus, 1966). Blood gas measurements were carried out midway through each measurement of cerebral blood flow.

Cerebral blood flow in the temporoparietal area of the right hemisphere was measured by the intracarotid ${ }^{133}$ Xenon technique (Rowan et al., 1970), using a well-collimated 1 inch $(25.4 \mathrm{~mm})$ sodium iodide crystal as a scintillation detector. Values for cerebral blood flow used in this study were derived from height over area analysis of a 10 minute clearance of isotope.

\section{EXPERIMENTAL PROTOCOL}

Because of variations in experimental subjects, methods of measuring cerebral blood flow, and in the extent and direction of the test stimuli, definitions of intact and impaired autoregulation must be clearly stated in any investigation. The criteria used in this study involved the change in cerebrovascular resistance which resulted from a rise in arterial pressure of $40 \mathrm{mmHg}$. Cerebrovascular resistance (CVR) was derived from:

$$
\mathrm{CVR}=\frac{\mathrm{CPP}}{\mathrm{CBF}}=\frac{\mathrm{SAP}-\mathrm{ICP}}{\mathrm{CBF}} \mathrm{mmHg} / \mathrm{ml} / \mathrm{min} \cdot 100 \mathrm{~g}
$$

Cerebrovascular conductance (CVC) was also calculated in these experiments from:

$$
\mathrm{CVC}=\frac{\mathrm{CBF}}{\mathrm{SAP}-\mathrm{ICP}} \mathrm{ml} \cdot \mathrm{cm}^{2} / \text { dynes } / \mathrm{s} \times 10^{-6}
$$

(Rodbard, 1971)

where $\mathrm{CBF}=$ cerebral blood flow, $\mathrm{CPP}=$ cerebral perfusion pressure, SAP $=$ systemic arterial pressure, and $\mathrm{ICP}=$ intracranial pressure.

Autoregulation was defined as intact if there was a rise in cerebrovascular resistance of more than $20 \%$ after the increase in arterial pressure. Any lesser change in resistance was categorized for the purpose of this study as impaired autoregulation.

Two control flow measurements were first carried out. Noradrenaline $(2 \mathrm{mg}$ in $200 \mathrm{ml} \mathrm{5 \%}$ dextrose solution) was infused into a high aortic catheter using a slow infusion apparatus and adjusted to increase mean arterial pressure by $40-50 \mathrm{mmHg}$. A third cerebral blood flow measurement was carried out 10 minutes later as a test of autoregulation. After this test, arterial pressure was allowed to subside and a further control flow measurement was made.

Judged by the criteria for autoregulation used in this study five of the 10 baboons had intact autoregulation on preliminary testing and five did not. There was no apparent reason for the impairment of autoregulation in two of the latter group. In one baboon with a high resting blood pressure (118 $\mathrm{mmHg}$ ), the induced arterial hypertension (173 $\mathrm{mmHg}$ ) probably exceeded the threshold for 'breakthrough' of autoregulation (Strandgaard et al., 1974). The remaining two baboons were deliberately subjected to short periods of anoxia in order to produce two groups, each of five animals, with 'intact' and with 'impaired' autoregulation.

After marking the position of the scintillation counter, it was moved to one side. A brass cylinder $1.5 \mathrm{~cm}$ in diameter was applied hard against the skull in the right temporal area using electrode jelly to ensure an airtight seal; liquid nitrogen was poured into the cylinder for exactly 10 minutes. After thawing and removal of the cylinder, the scintillation counter was replaced, and measurements of cerebral blood flow made at 30 minutes and 60 minutes from the end of the freezing period. The cryogenic lesion and any developing oedema related to it were now judged to be within the 'field of view' of the collimator.

Intra-arterial noradrenaline was then administered and blood flow measured as before to test autoregulation in the now damaged cerebral hemisphere. A further sequence of post-lesion measurements was possible in seven of the 10 baboons.

Evans Blue solution was injected intravenously 30 minutes before the baboon was killed under anaesthesia. The brains were removed and sliced fresh to assess the extent of the acute cryogenic lesion and to inspect the track of the ventricular catheters to ascertain whether true intraventricular pressure recordings had been obtained.

\section{RESULTS}

TEST OF AUTOREGULATION BEFORE BRAIN INJURY (Table 1) In the five baboons defined as having intact autoregulation the increase in arterial pressure did, in fact, produce a variable increase in cerebral blood flow $(12 \pm 5 \mathrm{ml} / \mathrm{min} \cdot 100 \mathrm{~g})$, although this was not significant. There was a small but constant passive increase in intracranial pressure in response to the arterial hypertension $(3.6 \pm 0.5 \mathrm{mmHg} ; \mathrm{P}<0.005)$. The mean 
TABLE 1

EFFECT OF INDUCED ARTERIAL HYPERTENSION IN BABOONS WITH INTACT AND IMPAIRED AUTOREGULATION (M \pm SE)

\begin{tabular}{|c|c|c|c|c|}
\hline \multirow[t]{2}{*}{ Measurement (units) } & \multicolumn{2}{|c|}{ Intact $(n=5)$} & \multicolumn{2}{|c|}{ Impaired $(n=5)$} \\
\hline & Control & Experimental & Control & Experimental \\
\hline $\begin{array}{l}\text { Arterial } \mathrm{PCO}_{2}(\mathrm{mmHg}) \\
\text { Arterial pressure }(\mathrm{mmHg}) \\
\text { Intracranial pressure }(\mathrm{mmHg}) \\
\text { Cerebral perfusion pressure }(\mathrm{mmHg}) \\
\text { Cerebral blood flow }(\mathrm{ml} / \mathrm{min} \cdot 100 \mathrm{~g}) \\
\text { Cerebrovascular resistance }(\mathrm{mmHg} / \mathrm{ml} / \mathrm{min} \cdot 100 \mathrm{~g}) \\
\text { Cerebrovascular conductance }\left(\mathrm{ml} \cdot \mathrm{cm}^{2} / \mathrm{dyne} / \mathrm{s} \times 10^{-6}\right)\end{array}$ & $\begin{array}{r}39.1 \pm 1.0 \\
80.2 \pm 5.2 \\
10.0 \pm 1.3 \\
70.2 \pm 4.2 \\
55.0 \pm 5.1 \\
1.34 \pm 0.20 \\
10.08 \pm 1.39\end{array}$ & $\begin{aligned} & 38.7 \pm 1.2 \\
& 129.8 \pm 11.0 \dagger \\
& 13.6 \pm 1.6 \dagger \\
& 116.2 \pm 10.1 \dagger \\
& 67.0 \pm 5.6 \\
& 1.80 \pm 0.26 \dagger \\
& 7.48 \pm 0.99 \dagger\end{aligned}$ & $\begin{array}{l}39.7 \pm 0.8 \\
90.4 \pm 8.6 \\
13.0 \pm 3.4 \\
77.4 \pm 11.2 \\
51.4 \pm 7.2 \\
1.62 \pm 0.30 \\
8.97 \pm 1.90\end{array}$ & $\begin{aligned} & 40.9 \pm 1.1 \\
& 139.6 \pm 9.4 \ddagger \\
& 22.6 \pm 3.6 \dagger \\
& 117.0 \pm 9.8 \ddagger \\
& 81.6 \pm 16.2 * \\
& 1.67 \pm 0.31 \\
& 8.95 \pm 2.13\end{aligned}$ \\
\hline
\end{tabular}

* $\mathrm{P}<0.05$. $\quad+\mathrm{P}<0.01 . \quad \mp \mathrm{P}<0.001$.

TABLE 2

EFFECT OF FOCAL CRYOGENIC INJURY TO CEREBRAL CORTEX IN BABOONS WITH INTACT AND IMPAIRED AUTOREGULATION

\begin{tabular}{|c|c|c|c|c|c|c|}
\hline \multirow[t]{2}{*}{ Measurement (units) } & \multicolumn{3}{|c|}{ Autoregn intact $(n=5)$} & \multicolumn{3}{|c|}{ Autoregn impaired $(n=5)$} \\
\hline & Control & $30 \mathrm{~min}$ & $60 \mathrm{~min}$ & Control & $30 \mathrm{~min}$ & $60 \mathrm{~min}$ \\
\hline \multirow{5}{*}{$\begin{array}{l}\text { Arterial } \mathrm{PCO}_{2}(\mathrm{mmHg}) \\
\text { Arterial pressure }(\mathrm{mmHg}) \\
\text { Intracranial pressure }(\mathrm{mmHg}) \\
\text { Cerebral perfusion pressure } \\
\text { (mmHg) } \\
\text { Cerebral blood flow } \\
(\mathrm{ml} / \mathrm{min} \cdot 100 \mathrm{~g}) \\
\text { Cerebrovascular resistance } \\
\text { (mmHg/ml/min } 100 \mathrm{~g}) \\
\text { Cerebrovascular conductance } \\
\left(\mathrm{ml} \cdot \mathrm{cm}^{2} / \mathrm{dyne}_{\mathrm{s}} \times 10^{-6}\right)\end{array}$} & $\begin{array}{l}39.4 \pm 1.2 \\
80.7 \pm 6.6 \\
11.8 \pm 1.5\end{array}$ & $\begin{array}{l}39.3 \pm 1.0 \\
85.8 \pm 8.2 \\
28.6 \pm 5.1^{*}\end{array}$ & $\begin{array}{l}40.9 \pm 1.0 \\
89.0 \pm 8.7 \\
30.6 \pm 5.3^{*}\end{array}$ & $\begin{array}{l}41.1 \pm 1.0 \\
97.2 \pm 9.0 \\
14.3 \pm 2.9\end{array}$ & $\begin{array}{l}40.9 \pm 1.1 \\
98.2 \pm 11.5 \\
25.2 \pm 6.2^{*}\end{array}$ & $\begin{array}{l}39.9 \pm 0.7 \\
88.0 \pm 12.4 \\
23.4 \pm 4.9 *\end{array}$ \\
\hline & $68.9 \pm 5.1$ & $57.2 \pm 8.0$ & $58.4 \pm 9.1$ & $82.9 \pm 8.8$ & $73.0 \pm 15.0$ & $64.6 \pm 14.6$ \\
\hline & $60.2 \pm 6.1$ & $44.6 \pm 5.1^{*}$ & $40.4 \pm 7.6^{*}$ & $59.5 \pm 9.4$ & $45.8 \pm 7.7$ & $34.6 \pm 3.8^{*}$ \\
\hline & $1.09 \pm 0.24$ & $1.28 \pm 0.06$ & $1.56 \pm 0.22$ & $1.51 \pm 0.33$ & $1.78 \pm 0.39$ & $1.90 \pm 0.35$ \\
\hline & $11.02 \pm 1.26$ & $9.87 \pm 0.44$ & $8.78 \pm 1.40$ & $9.03 \pm 2.21$ & $11.77 \pm 4.68$ & $10.27 \pm 3.65$ \\
\hline
\end{tabular}

Measurements at 30 and 60 minutes after injury are compared with control levels.

$* \mathbf{P}<0.05$.

TABLE 3

EFFECT OF INDUCED ARTERIAL HYPERTENSION AFTER CRYOGENIC CORTICAL INJURY IN BABOONS WITH INTACT AND IMPAIRED AUTOREGULATION

\begin{tabular}{|c|c|c|c|c|}
\hline \multirow[t]{2}{*}{ Measurement (units) } & \multicolumn{2}{|c|}{ Intact $(n=8)$} & \multicolumn{2}{|c|}{ Impaired $(n=9)$} \\
\hline & Control & Experimental & Control & Experimental \\
\hline $\begin{array}{l}\text { Arterial } \mathrm{PCO}_{2}(\mathrm{mmHg}) \\
\text { Arterial pressure }(\mathrm{mmHg}) \\
\text { Intracranial pressure }(\mathrm{mmHg}) \\
\text { Cerebral perfusion pressure }(\mathrm{mmHg}) \\
\text { Cerebral blood flow }(\mathrm{ml} / \mathrm{min} \cdot 100 \mathrm{~g}) \\
\text { Cerebrovascular resistance }(\mathrm{mmHg} / \mathrm{ml} / \mathrm{min} \cdot 100 \mathrm{~g}) \\
\text { Cerebrovascular conductance }\left(\mathrm{ml} \cdot \mathrm{cm}^{2} / \mathrm{dyne} / \mathrm{s} \times 10^{-6}\right)\end{array}$ & $\begin{array}{l}40.4 \pm 0.8 \\
82.5 \pm 6.4 \\
22.6 \pm 5.1 \\
60.2 \pm 7.1 \\
46.1 \pm 6.5 \\
1.42 \pm 0.16 \\
9.81 \pm 1.40\end{array}$ & $\begin{aligned} & 39.9 \pm 0.6 \\
& 125.9 \pm 6.3 \ddagger \\
& 31.9 \pm 7.6 \dagger \\
& 94.0 \pm 7.6 \dagger \\
& 53.5 \pm 5.6 \\
& 1.84 \pm 0.14 \ddagger \\
& 7.06 \pm 0.52\end{aligned}$ & $\begin{array}{l}39.9 \pm 0.8 \\
93.7 \pm 8.9 \\
20.9 \pm 3.2 \\
72.8 \pm 10.6 \\
38.3 \pm 3.3 \\
1.98 \pm 0.29 \\
8.58 \pm 2.22\end{array}$ & $\begin{aligned} 40.3 & \pm 0.9 \\
137.1 & \pm 9.8 \ddagger \\
33.4 & \pm 6.2 \dagger \\
103.7 & \pm 10.4 \\
49.8 & \pm 6.1 * \\
2.33 & \pm 0.32 \\
6.77 & \pm 1.39\end{aligned}$ \\
\hline
\end{tabular}

$* P<0.05 . \quad+P<0.01 . \quad \mp P<0.001$.


increase in cerebrovascular resistance in these baboons was $34 \%$ during arterial hypertension, and was paralleled by a $26 \%$ reduction in cerebrovascular conductance.

In the five baboons in which autoregulation was judged to be impaired before the brain injury the induced change in arterial pressure which was used to test autoregulation $(49.2 \pm 4.8$ $\mathrm{mmHg}$ ) was the same as in the 'intact' group $(49.6 \pm 8.0 \mathrm{mmHg})$. There was, however, a greater passive increase in intracranial pressure $(9.6 \pm 2.0 \mathrm{mmHg} ; \mathrm{P}<0.01)$ and of cerebral blood flow $(30 \pm 12 \mathrm{ml} / \mathrm{min} \cdot 100 \mathrm{~g} ; P<0.05)$ with no change in cerebrovascular resistance $(2 \%)$ or conductance $(0.2 \%)$ during arterial hypertension.

Before cryogenic brain injury the significant differences between the autoregulating and nonautoregulating groups of baboons were confined to the changes in cerebrovascular resistance $(t=$ $4.8 ; \mathrm{P}<0.001)$ and conductance $(\mathrm{t}=4.7 ; \mathrm{P}<$ $0.005)$ during arterial hypertension. There were no differences in resting levels of arterial $\mathrm{PCO}_{2}$, blood pressure, intracranial pressure, or cerebral blood flow.

EFFECTS OF ACUTE CRYOGENIC BRAIN INJURY (Table 2) Overall, the effect of the brain injury was to reduce cerebral blood flow and to increase intracranial pressure and it is tempting to draw conclusions about cause and effect which closer inspection of the data shows to be misleading. The increases in intracranial pressure were very variable, ranging from 6 to $35 \mathrm{mmHg}$. Since arterial pressure was not greatly affected, the cerebral perfusion pressure was subject to a variable reduction. The reductions in cerebral blood flow were not closely related to changes in intracranial pressure or perfusion pressure, however, since there was a greater reduction in flow than in perfusion pressure. Thus, in the five baboons with intact autoregulation, there was a $17 \%$ fall in perfusion pressure over the 30 minutes after production of the lesion, but a $26 \%$ fall in blood flow resulting in a $17 \%$ increase in cerebrovascular resistance. In the five baboons with impaired autoregulation the results were similar with a $12 \%$ fall in cerebral perfusion pressure, and $23 \%$ fall in cerebral blood flow, producing an $18 \%$ increase in cerebrovascular resistance. The increases in resistance implied that flow was being decreased by some mechanism other than increased intracranial pressure and decreased perfusion pressure. There was no change in arterial $\mathrm{PCO}_{2}$ in either group.

The changes in cerebral blood flow between 30 and 60 minutes from the production of the acute brain injury also pointed to some degree of pressure-flow dissociation. In the four baboons which had the greatest reductions of cerebral blood flow (mean change from 43 to $29 \mathrm{ml} /$ $\mathrm{min} \cdot 100 \mathrm{~g}$ ) and the greatest increases in cerebrovascular resistance $(1.55$ to $2.18 \mathrm{mmHg} / \mathrm{ml} /$ $\mathrm{min} \cdot 100 \mathrm{~g})$ the changes in intracranial pressure $(28$ to $30 \mathrm{mmHg}$ ) and cerebral perfusion pressure (69 to $65 \mathrm{mmHg}$ ) were minimal. Two of these baboons were in the 'intact' autoregulation group and two in the 'impaired' group. Again, the mechanism responsible for at least part of the reduction in cerebral blood flow in these animals did not appear to relate closely to intracranial or cerebral perfusion pressure.

Changes in brain after cryogenic injury There was an obvious brain lesion in every baboon corresponding to the site of application of the liquid nitrogen container. The lesions were soft and in parts obviously necrotic, $25-35 \mathrm{~mm}$ in diameter, and $3-10 \mathrm{~mm}$ in depth. There was no difference in the extent of the lesions for baboons in the autoregulating and non-autoregulating groups. Staining with Evans Blue indicated only the size of the acute lesion because the solution was injected only a short time before the animals were killed under anaesthesia.

TEST OF AUTOREGULATION AFTER BRAIN INJURY (Table 3) When autoregulation of cerebral blood flow to induced arterial hypertension was again tested after the brain injury in the baboons with previously intact autoregulation, there was a smaller increase in cerebral blood flow $(7 \pm 4 \mathrm{ml} /$ $\mathrm{min} \cdot 100 \mathrm{~g}$ ) compared with the change in flow before the brain injury $(12 \mathrm{ml} / \mathrm{min} \cdot 100 \mathrm{~g})$ despite the fact that the induced increases in arterial pressure before and after the lesion were similar (49 and $43 \mathrm{mmHg}$ respectively). There was, however, a greater passive increase in intracranial pressure during arterial hypertension after the lesion $(9.3 \pm 1.7 \mathrm{mmHg})$ compared with 3.6 $\mathrm{mmHg}$ before the lesion $(\mathrm{P}<0.001)$. There was 
therefore a smaller increase in cerebral perfusion pressure, so that the post-lesion increase in cerebrovascular resistance of $36 \%$ and decrease in cerebrovascular conductance of $26 \%$ were almost exactly the same as those produced by elevation of the blood pressure before brain damage had occurred $(34 \%$ and $26 \%$ respectively).

In the five baboons in which autoregulation was impaired before the brain injury the difference in the changes during induced arterial hypertension before and after brain damage had occurred were more striking. Cerebral blood flow rose less than half as much after injury $(11 \pm 4 \mathrm{ml} / \mathrm{min} \cdot 100 \mathrm{~g})$ as before $(30 \mathrm{ml} / \mathrm{min} \cdot 100$ g), although the increases in blood pressure before and after injury were again similar (49 and $43 \mathrm{mmHg}$ respectively). This increase in cerebral blood flow is similar to that observed in the baboons categorized as having intact autoregulation before brain injury. There was, however, a significant increase in intracranial pressure during the rise in blood pressure $(12.5 \pm 3.4$ $\mathrm{mmHg}$ ) so that cerebral perfusion pressure did not increase after the lesion $(31 \mathrm{mmHg}$ ) by as much as before $(40 \mathrm{mmHg})$. Nevertheless, there was a $17 \%$ increase in cerebrovascular resistance during arterial hypertension after brain injury which was consistent (paired $t=4.6$; $\mathbf{P}<0.005$ ) and a corresponding $21 \%$ fall in cerebrovascular conductance.

\section{CONCLUSIONS}

By measuring the changes in cerebrovascular resistance resulting from induced arterial hypertension, it was possible to distinguish two groups of baboons as having intact and impaired autoregulation. These groups differed only in the response of cerebral blood flow, intracranial pressure, and cerebrovascular resistance and conductance to the rise in blood pressure; resting levels of all variables were the same in both groups.

A standardized brain lesion was then produced in all animals. This was sufficiently severe to produce an increase in intraventricular pressure and a reduction in blood flow in the involved cerebral hemisphere, with further depression of flow and increase in cerebrovascular resistance between 30 and 60 minutes. Postmortem observa- tions confirmed that a clearly defined lesion was present in every baboon.

Despite this unequivocal brain damage, an induced increase in arterial pressure after the brain injury produced an increase in cerebrovascular resistance, whether or not this response had been present before the injury. In the baboons in which autoregulation had been intact before the brain injury, the increase in cerebrovascular resistance after injury was sufficiently great $(>20 \%)$ to be classified as 'intact autoregulation', suggesting, according to the definition used, that this normal physiological response had been preserved despite definite brain damage in the territory in which blood flow was being measured. In baboons which did not exhibit autoregulation before injury, testing after injury suggested partial restoration of the autoregulatory response.

An increase in cerebrovascular resistance during arterial hypertension in the presence of brain damage is, however, very unlikely to be the normal autoregulatory response. In many instances the rise in arterial pressure after brain injury was associated with considerable ino creases in intracranial pressure (range 3-3 $\mathrm{mmHg}$; mean $11 \mathrm{mmHg}$ ). Such increases i. intracranial pressure could not, however, be incriminated as the cause of increased cerebrovascular resistance, since this was calculated from cerebral perfusion pressure, thus taking account of changes in intracranial pressure. Moreover, there was poor correlation between the extent of the passive increase in intracranial pressure during arterial hypertension and the changes in cerebrovascular resistance. Thus the average increase in intracranial pressure which occurred during arterial hypertension after injury in baboons with a greater than $20 \%$ increase in cerebrovascular resistance was 9.6 $\mathrm{mmHg}$, whereas in those animals with less than $20 \%$ increase in resistance the average increase in intracranial pressure was actually greater at $12.5 \mathrm{mmHg}$.

It is possible that brain tissue pressure increased during arterial hypertension to a greater o extent than intraventricular pressure. If it is $\tilde{N}$ postulated that venous pressure might also have $\underset{\omega}{N}$ risen well beyond intraventricular pressure, so that cerebral perfusion pressure was actually lower than the values calculated from the arterial- 
intracranial pressure difference. Post-injury levels of cerebral blood flow which did not increase much during arterial hypertension might have reflected simply a passive response to unchanged perfusion pressure. We have calculated by how much more than the recorded intraventricular pressure brain tissue pressure would need to have risen to explain the present results on this basis, and find that brain tissue pressure would have to have risen on average by $19 \mathrm{mmHg}$ more than intraventricular pressure (range 0-45 $\mathrm{mmHg}$ ) to have caused no increase in calculated cerebrovascular resistance during increased arterial pressure. Although this is possible, it is unlikely that such a pressure differential could have developed and been maintained during the time necessary for measurement of cerebral blood flow. Certainly there was no evidence of a pressure differential between the recordings from the left and right lateral ventricles.

We conclude that an increase in calculated cerebrovascular resistance which accompanies induced arterial hypertension in the presence of known brain damage may not necessarily indicate that the normal autoregulatory mechanism is intact. The mechanism of these changes is not clear from the current study but cannot be simply related to passive increases in intracranial pressure.

\section{COMMENT}

Autoregulation of blood flow is a fundamental property of the normal brain, the purpose of which seems to be to ensure a steady brain energy supply despite alterations of cerebral perfusion pressure. It is a biological paradox, therefore, that this important mechanism should be so easily disturbed by brain trauma and ischaemia. It would appear, then, that in patients with head injury, stroke, and brain tumours, blood flow at least in the damaged areas would be pressure-passive and indeed many studies confirm that this is often the case (Fieschi, 1972).

As experience with cerebral blood flow measurements increases, however, so does the incidence of reports which point to varying degrees of pressure-flow dissociation within the brain. Thus, in an early study, Kety et al. (1948) showed that cerebral blood flow was reduced in patients with intracranial hypertension only when intracranial pressure exceeded $30 \mathrm{mmHg}$. In these same patients, however, when intracranial pressure was abruptly reduced by aspiration of ventricular CSF, cerebral blood flow did not increase; intravenous infusion of hypertonic glucose solution, on the other hand, often improved cerebral blood flow as intracranial pressure decreased (Shenkin et al., 1948). Bruce et al. (1973) made similar observations after administration of hypertonic mannitol solution to comatose patients, pointing out that increases in cerebral blood flow tended to be greatest in patients who had little or no reduction in intracranial pressure, rather than in those with large decreases in pressure. Cronqvist and Lundberg (1968) studied cerebral blood flow during episodic waves of severe intracranial hypertension (plateau waves) in patients with brain tumours. Cerebral blood flow decreased at the height of these pressure waves and increased as the pressure waves spontaneously subsided. If the wave were aborted by tapping ventricular CSF to reduce intracranial pressure suddenly, there was no increase in cerebral blood flow. In these examples sudden increases in cerebral perfusion pressure in circumstances when autoregulation might be expected to be impaired failed to induce the expected increase in flow.

Another example of pressure-flow dissociation occurs in cerebral oedema where cerebral blood flow becomes severely reduced at a stage when intracranial pressure is only moderately raised. There is in fact a closer relationship between reduced cerebral blood flow and the increase in brain water content than between pressure and flow. This has been shown in osmotic oedema in experimental animals (Meinig et al., 1973) and in peritumoural oedema in patients (Reulen et al., 1972).

The present study has shown that, in circumstances in which autoregulation would be expected to be impaired, cerebral blood flow may not rise much despite induced increases in both arterial pressure and cerebral perfusion pressure. Although it is not possible at this stage to pinpoint the mechanism of apparent resistance changes in damaged brain, the observation is of potential importance on two counts. First, in determining the severity of any derangement of the cerebral circulation, it is usual to consider that intact autoregulation is of favourable 
prognostic significance and impaired autoregulation unfavourable. This study suggests that apparently intact autoregulation may be present in damaged brain and cannot therefore always be a favourable sign. Secondly, in such cases, induced increases in arterial pressure do not improve cerebral blood flow even when perfusion pressure increases; induced arterial hypertension is therefore unlikely to be useful in the prevention or amelioration of patchy cerebral ischaemia in patients with head injury. Since arterial hypertension increases brain elastance and decreases compliance when intracranial pressure is even moderately raised, further severe rises in intracranial pressure are more liable to occur (Leech and Miller, 1974). Furthermore, in cold-induced and other forms of vasogenic oedema the effect of arterial hypertension is to accelerate the spread of extracellular oedema fluid (Klatzo et al., 1967). Induced increases in blood pressure are on this evidence not only unhelpful for improving cerebral blood flow, but may actually be dangerous and are therefore contraindicated in patients with severe brain damage.

This investigation was supported by the Secretary of State for Scotland's Fund for Medical Research.

\section{REFERENCES}

Brock, M. (1968). Regional cerebral blood flow (rCBF) changes following local brain compression in the cat. Scandinavian Journal of Clinical and Laboratory Investigation, Suppl. 102, 14: A.

Bruce, D. A., Langfitt, T. W., Miller, J. D., Schutz, H., Vapalahti, M. P., Stanek, A., and Goldberg, H. I. (1973). Regional cerebral blood flow, intracranial pressure, and brain metabolism in comatose patients. Journal of Neurosurgery, 38, 131-144.

Clasen, R. A., Brown, D. V. L., Leavitt, S., and Hass, G. M. (1953). The production by liquid nitrogen of acute closed cerebral lesions. Surgery, Gynecology, and Obstetrics, 96, 605-616.

Cronqvist, S., and Lundberg, N. (1968). Regional cerebral blood flow in intracranial tumours with special regard to cases with intracranial hypertension. Scandinavian Journal of Clinical and Laboratory Investigation, Suppl. 102, 15: A.

Farrar, J. K., Jr, and Roach, M. R. (1973). The effects of raised intracranial pressure on flow through major cerebral arteries in vitro. Stroke, 4, 795-806.

Fieschi, C. (1972). Cerebral Blood Flow and Intracranial Pressure, pp. 620. Karger: Basel.

Graham, D. I., and Adams, J. H. (1971). Ischaemic brain damage in fatal head injuries. In Brain Hypoxia, pp. 34-40. Edited by J. B. Brierley and B. S. Meldrum. Clinics in Developmental Medicine No. 39/40. Heinemann: London.

Häggendal, E., Löfgren, J., Nilsson, N. J., and Zwetnow, N. N. (1970). Effects of varied cerebrospinal fluid pressure on cerebral blood flow in dogs. Acta Physiologica Scandinavica, 79, 262-271.

Harper, A. M. (1966). Autoregulation of cerebral blood flow: influence of arterial blood pressure on the blood flow through the cerebral cortex. Journal of Neurology, Neurosurgery, and Psychiatry, 29, 398-403.

Jennett, B., Graham, D. I., Adams, H., and Johnston, I. H. (1973). Ischemic brain damage after fatal blunt head injury. In Cerebrovascular Diseases. Eighth Conference, pp. 163-170. Edited by F. H. McDowall and R. W. Brennan. Grune and Stratton: New York.

Johnson, P. C. (1964). Review of previous studies and current theories of autoregulation. Circulation Research, 15, Suppl. 1, 2-9.

Johnston, I. H., Johnston, J. A., and Jennett, B. (1970). Intracranial-pressure changes following head injury. Lancet, 2, 433-436.

Johnston, I. H., and Rowan, J. O. (1974). Raised intracranial pressure and cerebral blood flow. 3. Venous outflow tract pressures and vascular resistances in experimental intracranial hypertension. Journal of Neurology, Neurosurgery, and Psychiatry, 37, 392-402.

Johnston, I. H., Rowan, J. O., Harper, A. M., and Jennett, W. B. (1972). Raised intracranial pressure and cerebral blood flow. 1. Cisterna magna infusion in primates. Journal of Neurology, Neurosurgery, and Psychiatry, 25, 285-296.

Johnston, I. H., Rowan, J. O., Harper, A. M., and Jennett, W. B. (1973). Raised intracranial pressure and cerebral blood flow. 2. Supratentorial and infratentorial mass lesions in primates. Journal of Neurology, Neurosurgery, and Psychiatry, 36, 161-170.

Kety, S. S., Shenkin, H. A., and Schmidt, C. F. (1948). The effects of increased intracranial pressure on cerebrab circulatory functions in man. Journal of Clinical Investiga tion, 27, 493-499.

Klatzo, I., Wisniewski, H., Steinwall, O., and Streicher, E (1967). Dynamics of cold injury edema. In Brain Edema, pp? 554-563. Edited by I. Klatzo and F. Seitelberger. Springer: Berlin.

Leech, P., and Miller, J. D. (1974). Intracranial volumepressure relationships during experimental brain compression in primates. 2. Effect of induced changes in systemic arterial pressure and cerebral blood flow. Journal of Neurology, Neurosurgery, and Psychiatry, 37, 1099-1104.

Meinig, G., Reulen, H. J., and Magawly, C. (1973). Regional cerebral blood flow and cerebral perfusion pressure in global brain edema induced by water intoxication. Acta Neurochirurgica, 29, 1-13.

Miller, J. D., Ledingham, I. McA., and Jennett, W. B. (1970). Effects of hyperbaric oxygen on intracranial pressure and cerebral blood flow in experimental cerebral oedema. Journal of Neurology, Neurosurgery, and Psychiatry, 33, 745-755.

Miller, J. D., Stanek, A. E., and Langfitt, T. W. (1972), Concepts of cerebral perfusion pressure and vascular compression during intracranial hypertension. In Cerebral Blood Flow, Progress in Brain Research, vol. 35, pp. 411432. Edited by J. S. Meyer and J. P. Schade. Elsevier: Amsterdam.

Miller, J. D., Stanek, A. E., and Langfitt, T. W. (1973). Cerebral blood flow regulation during experimental brain compression. Journal of Neurosurgery, 39, 186-196.

Overgaard, J., and Tweed, W. A. (1974). Cerebral circulation after head injury. Part I: Cerebral blood flow and its regulation after closed head injury with emphasis on clinical correlations. Journal of Neurosurgery, 41, 531-541. Rapela, C. E., and Green, H. D. (1964). Autoregulation of canine cerebral blood flow. Circulation Research, 15, Suppl. 1, 205-212. 
Reivich, M., Marshall, W. J. S., and Kassell, N. (1969), Loss of autoregulation produced by cerebral trauma. In Cerebral Blood Flow, pp. 205-208. Edited by M. Brock. C. Fieschi, D. H. Ingvar, N. A. Lassen, and K. Schürmann. Springer: Berlin.

Reulen, H. J., Hadjidimos, A., and Schürmann, K. (1972). The effect of dexamethasone on water and electrolyte content and rCBF in perifocal brain edema in man. In Steroids and Brain Edema, pp. 239-252. Edited by H. J. Reulen and K. Schürmann. Springer: Berlin.

Rodbard, S. (1971). The burden of the resistance vessels. Circulation Research, 28, Suppl. 1, 2-8.

Rowan, J. O., Harper, A. M., Miller, J. D., Tedeschi, G. M., and Jennett, W. B. (1970). Relationship between volume flow and velocity in the cerebral circulation. Journal of Neurology, Neurosurgery, and Psychiatry, 33, 733-738.

Severinghaus, J. W. (1966). Blood gas calculator. Journal of Applied Physiology, 21, 1108-1116.

Shenkin, H. A., Spitz, E. B., Grant, F. C., and Kety, S. S. (1948). The acute effects on the cerebral circulation of the reduction of increased intracranial pressure by means of intravenous glucose or ventricular drainage. Journal of Neurosurgery, 5, 466-470.

Shulman, K. (1965). Small artery and vein pressures in the subarachnoid space of the dog. Journal of Surgical Research, 5, 56-61.

Strandgaard, S., MacKenzie, E. T., Sengupta, D., Rowan, J. O., Lassen, N. A., and Harper, A. M. (1974). Upper limit of autoregulation of cerebral blood flow in the baboon. Circulation Research, 34, 435-440.

Symon, L., Pasztor, E., Dorsch, N. W. C., and Branston, N. M. (1973). Physiological responses of local areas of the cerebral circulation in experimental primates determined by the method of hydrogen clearance. Stroke, 4, 632-642. Troupp, H. (1965). Intraventricular pressure in patients with severe brain injuries. Journal of Trauma, 5, 373-378.

Yada, K., Nakagawa, Y., and Tsuru, M. (1973). Circulatory disturbance of the venous system during experimental intracranial hypertension. Journal of Neurosurgery, 39, 723-729. 